\title{
Neuromonitoring during cardiothoracic surgery: The signal and the noise
}

Abe DeAnda, Jr, MD

See related article on pages 3204-10.

Neurologic complications in the perioperative period for patients undergoing cardiac surgery are associated with significant morbidity and mortality. Even when a stroke is not clinically evident, lesser degrees of postoperative cognitive dysfunction may be noticed by the patient or detected by robust neurocognitive testing, and such level of dysfunction may be one of the more common adverse outcomes after cardiac surgery. ${ }^{1}$ Cardiac surgical procedures can affect the regional or global perfusion of the brain in 1 of 2 ways, either by gaseous or particulate embolization from a proximal site or a decrease in perfusion due to pressure or flow perturbations. The latter appears to be the more common cause and can be the most easily manipulated or intervened on by the operative team. Low-density (typically 2 or 4 channels) near-infrared reflectance spectroscopy (NIRS) is currently used to assess the regional cortical oxygen saturation of the frontal lobes, and this information is extrapolated to global cerebral perfusion. Perioperative cerebral oxygen desaturations as measured with NIRS have been shown to have an impact on longer-term neurologic outcomes. ${ }^{2}$ Murkin and colleagues ${ }^{3}$ and others ${ }^{2}$ have documented that interventions made intraoperatively in response to a decrease in regional saturation $\left(\mathrm{rSO}_{2}\right)$ can alone or in combination result in a return toward baseline saturation, and thus a decrease in the potential for neurologic injury. These interventions are not necessarily complex; the "Murkin Interventions" consist of repositioning the head, increasing pump flow, increasing the mean arterial pressure, normalizing the arterial carbon dioxide tension, deepening anesthesia, increasing the inspired oxygen fraction, and providing pulsatile perfusion. In some situations, transfusion of red blood cells also might be considered.

In this issue of the Journal, Lee and colleagues ${ }^{4}$ take NIRS monitoring a few steps further, combining a significantly

From the New York University Langone Medical Center, New York, NY.

Disclosures: Abe DeAnda has received consulting/travel fees from Somanetics Corporation as a participant in a medical advisory board meeting, but has no stock equity, ongoing consulting agreements, or other financial interests in Somanetics or any other neuromonitoring company.

Received for publication Sept 18, 2014; accepted for publication Sept 18, 2014; available ahead of print Oct 16, 2014.

Address for reprints: Abe DeAnda, Jr, MD, NYU Langone Medical Center, 530 First Ave, Suite 9V, New York, NY 10016 (E-mail: abe.deanda@nyumc.org).

J Thorac Cardiovasc Surg 2014;148:3211-2

$0022-5223 / \$ 36.00$

Copyright (c) 2014 by The American Association for Thoracic Surgery

http://dx.doi.org/10.1016/j.jtcvs.2014.09.060 larger array with post hoc tomographic reconstruction, postprocedure magnetic resonance imaging, and postmortem histopathology to allow the authors to validate the highdensity NIRS imaging spatial features. As fate would have it, 2 of the 5 animals in this study inadvertently experienced a significant hemorrhage, adding further to the dataset. The result is a tool that can provide high-resolution real-time information about regional and global cerebral oxygen saturation in contrast to existing technologies that require the user to assume that the regional (ie, frontal lobe) saturation reflects other parts of the brain. The implication is that with the data-rich feedback and using the modified $z$ score to determine significant changes from baseline, earlier and perhaps more appropriate interventions could be implemented by the perfusionist or anesthesiologist. Adding to this is the welcomed news that presumptively for humans, the scalp will not have to be removed to insert the sensors!

Lee and colleagues ${ }^{4}$ have nicely demonstrated an enhancement in intraoperative neuromonitoring that by all measures may have a direct impact on patient management. With any new or enhanced monitoring device, the challenge is both literally and figuratively separating the signal from the noise. The authors' modified $z$ score appears to have the fidelity to detect changes in regional cerebral oxygenation; however, this measurement would need to be tested and validated in humans, as they acknowledge in their article. The difficulty comes in the next step-what to do with the data in real time during the surgical procedure? NIRS is already seen in many operating rooms, but the extent that it is used to actually change the conduct of the operation is unclear. When to intervene also is unclear because there is no well-defined parameter threshold. For example, Ono and colleagues ${ }^{5}$ combined NIRS with continuous mean arterial blood pressure monitoring to calculate the area under the curve of the product of the duration and magnitude of systemic blood pressure below the limits of autoregulation and found the area under the curve to correspond to an increase in morbidity or mortality, but no intervention threshold was noted. The prospective protocol of Murkin and colleagues ${ }^{3}$ was geared toward maintaining $\mathrm{rSO}_{2}$ at or greater than $75 \%$ baseline; cerebral desaturation was defined as a decrease in $\mathrm{rSO}_{2}$ at less than $70 \%$ of baseline for 1 minute or longer, and an intervention was performed when the $\mathrm{rSO}_{2}$ was less than $75 \%$ for more than 15 seconds. Slater and colleagues ${ }^{6}$ intervened when the $\mathrm{rSO}_{2}$ decreased to less than $80 \%$ baseline. With the dramatic increase in channels with Lee and colleagues' system, ${ }^{4}$ choosing when to intervene would need to reflect 
the increase in data input, and unfortunately the increase in the corresponding noise. The authors have already demonstrated their ability to handle one engineering feat; this second one should be no less daunting or successful.

\section{References}

1. Lombard FW, Mathew JP. Neurocognitive dysfunction following cardiac surgery. Semin Cardiothorac Vasc Anesth. 2010;14:102-10.

2. Hoffman GM, Brosig CL, Mussatto KA, Tweddel JS, Ghanayem NS. Perioperative cerebral oxygen saturation in neonates with hypoplastic left heart syndrome and childhood neurodevelopmental outcome. J Thorac Cardiovasc Surg. 2013; 146:1153-64.
3. Murkin JM, Adams SJ, Novick RJ, Quantz M, Bainbridge D, Iglesias I, et al. Monitoring brain oxygen saturation during coronary bypass surgery: a randomized, prospective study. Anesth Analg. 2007;104:51-8.

4. Lee DC, Gevorgyan T, Graber HL, Pfeil DS, Xu Y, Mangla S, et al. Feasibility of near infrared spectroscopic tomography for intraoperative functional cerebral monitoring: a primate study. J Thorac Cardiovasc Surg. 2014; 148:3204-10.

5. Ono M, Brady K, Easley RB, Brown C, Kraut M, Gottesman RF, et al. Duration and magnitude of blood pressure below cerebral autoregulation threshold during cardiopulmonary bypass is associated with major morbidity and operative mortality. J Thorac Cardiovasc Surg. 2014;147:483-9.

6. Slater JP, Guarino T, Stack J, Vinod K, Bustami RT, Brown JM, et al. Cerebral oxygen desaturation predicts cognitive decline and longer hospital stay after cardiac surgery. Ann Thorac Surg. 2009;87:36-45. 